\title{
L'interféron-gamma : une cytokine antifibrosante qui possède un site de fixation dans la matrice extracellulaire
}

\author{
J.A. GRIMAUD, H. LORTAT-JACOB \\ CNRS URA 1459, institut Pasteur, avenue Tony Garnier, \\ 69365 Lyon Cedex 7
}

L'interféron-gamma (IFN-gamma) régule la synthèse des protéines de la matrice extracellulaire. En effet, cette cytokine sur des fibroblastes en culture diminue l'expression des molécules de collagènes (notamment I et III), en même temps qu'elle augmente la synthèse de la collagénase et qu'elle diminue l'activité du TIMP-1 [1]. L'IFN-gamma pourrait dónc être utilisé en pathologie comme antifibrosant. In vivo, avant d'atteindre sa cellule cible, I'IFN-gamma doit traverser la matrice extracellulaire. L'existence d'interactions entre cette structure et l'IFN-gamma a été recherchée. Cette première approche a permis de constater la présence de sites de fixation pour l'IFN-gamma $\left(\mathrm{Kd}=10^{-9} \mathrm{M}\right)$ dans les matrices extracellulaires. De plus, l'activité biologique de l'IFN-gamma fixé sur une telle matrice est supérieure à celle de l'IFN-gamma en solution. Ce "récepteur matriciel" à I'IFN-gamma est localisé sur les chaînes héparane sulfate (HS) de certains protéoglycanes de la matrice [2]. Du côté interféron, c'est un petit groupe d'acides aminés ( ${ }^{125}$ Lys- ${ }^{132}$ Ser) de l'extrémité C-terminale de la protéine qui interagit avec l'HS. Enfin, une fois fixé à I'HS, I'IFN-gamma est protégé des dégradations enzymatiques [3]. Ces observations permettent de définir un rôle nouveau pour les matrices extracellulaires : ces structures interviennent de façon active dans les échanges cellulaires et sont le siège de concentrations locales de cytokines, permettant une stimulation focalisée et continue des cellules cibles. Elles peuvent représenter un "réservoir physiologique" d'IFNgamma stocké sous forme stable et protégé. L'ensemble de ces données montre l'importance de la matrice dans les échanges cellulaires et permet d'introduire la notion de régulation locale par les éléments de la matrice dans l'environnement cellulaire [4].

[1] Melin M., Andujar M., Lortat-Jacob H., Hartmann D., Grimaud J.A. (à paraître).

[2] Lortat-Jacob H., Kleinman H.K., Grimaud J.A. J. Clin. Invest., 1991, 87, 878-883.

[3] Lortat-Jacob H., Grimaud J.A. FEBS Lett., 1991, 280, 152-154.

[4] Lortat-Jacob H., Grimaud J.A. Cell. Mol. Biol., 1991, 37, 253-260. 